\title{
REVISÃo de LITERATURA Transtorno do espectro autista e a suplementação por ácido fólico antes e durante a gestação
}

\author{
Autism spectrum disorder and folic acid supplementation \\ before and during pregnancy \\ Carina Scanoni Maia' \\ https://orcid.org/0000-0002-8192-5018 \\ Karina Maria Campello de Menezes ${ }^{2}$ \\ https://orid.org/0000-0002-5043-3192 \\ Fernanda das Chagas Angelo Mendes Tenorio \\ https://orid.org/0000-0002-5808-5786 \\ José Reginaldo Alves de Queiroz Júnior \\ https://orcid.org/0000-0002-3122-4192 \\ Gyl Everson de Souza Maciel $\left.\right|^{4}$ \\ https://orcid.org/0000-0001-8998-5253
}

\section{RESUMO}

Objetivo: Elucidar se a suplementação com ácido fólico pouco antes da concepção e/ou durante a gestação pode estar realmente atrelado ao desenvolvimento do transtorno do espectro autista (TEA). Metódos: Foi realizada uma revisão de literatura em base de dados, nos idiomas português e inglês, durante o período de novembro de 2017 até abril de 2018, com ênfase nas publicações mais recentes. Resultados: Do total de 174 artigos, 87 compuseram este trabalho. Pesquisas apontam que o aumento dos casos de TEA se deve ao fato de que mais fatores genéticos estejam implicados na etiopatogênese neural. No entanto,

\section{Palavras-chave}

Transtorno do espectro autista, suplementos pré-natais, ácido fólico, embriogênese, desenvolvimento mental. a grande maioria dos artigos ressalta com maior precisão que há mais efeitos benéficos do uso de ácido fólico antes da concepção e durante a gestação na prevenção do TEA, assim como de outras anormalidades relacionadas aos defeitos do tubo neural. Conclusão: Quando se analisa o risco-benefício da suplementação com ácido fólico nas doses recomendadas, 0,4 a 0,8 mg/dia, conclui-se que os benefícios sobrepujam os possíveis riscos de desenvolver o TEA.

\section{ABSTRACT}

Objective: Elucidating whether supplementation with folic acid shortly before conception and/or during pregnancy may actually be linked to the development of Autistic Spectrum Disorder (ASD). Methods: A literature review was conducted in the Portuguese and English languages during the period from November 2017 to April 2018, with emphasis on the most recent publications. Results: Of the total of 174 articles, 87 compose this work. Research indicates that the increase in ASD cases should take into account the fact that more genetic factors are implicated in neural pathogenesis. However, a large majority of articles point

1 Universidade Federal de Pernambuco (UFPE), Centro de Biociências, Departamento de Histologia e Embriologia, Recife, PE, Brasil. 2 Universidade Federal de Pernambuco (UFPE), Centro de Biociências, Recife, PE, Brasil. 3 Universidade Federal de Pernambuco (UFPE), Centro de Ciências Médicas, Recife, PE, Brasil.

4 Universidade Federal de Pernambuco (UFPE), Centro de Ciências da Saúde, Programa de Pós-Graduação em Fisiologia e Bioquímica, Recife, PE, Brasil. 


\section{Keywords}

Autism, prenatal supplements, folic acid, embryogenesis, autism spectrum disorder, mental development. out that there are more beneficial effects of using folic acid before application and during pregnancy in the prevention of ASD, as well as other abnormalities related to neural tube defects. Conclusion: When analyzing the risk-benefit of folic acid supplementation at the recommended doses, 0.4 to $0.8 \mathrm{mg} / \mathrm{day}$, it is concluded that the benefits outweigh the possible risks of developing ASD.

\section{INTRODUÇÃO}

O autismo é um distúrbio relacionado ao desenvolvimento humano, o qual vem sendo estudado pelos cientistas há mais de 60 anos. Porém, ainda há bastantes divergências e questões a serem respondidas pelo meio científico'. De acordo com os dados do CDC (Center of Diseases Control and Prevention), órgão ligado ao governo dos Estados Unidos, existe hoje um caso de autismo a cada 110 pessoas². Assim, estima-se que o Brasil, com cerca de 200 milhões de habitantes, possua em torno de 2 milhões de autistas.

Em virtude da sua complexidade, conjunto de sintomas e variáveis, atualmente o autismo está inserido no grupo de transtornos de espectro autista (TEA), de acordo com o Manual Diagnóstico e Estatístico de Transtornos Mentais (2013). O TEA pode ser identificado antes mesmo dos 3 anos de idade, ao longo do desenvolvimento da criança em relação às interações sociais e à comunicação, por exemplo, o que tem influência na sua capacidade de adaptação às situações do dia a dia'.

Atualmente, é possível identificar alterações genéticas que podem acarretar o desenvolvimento de TEA nas crianças, porém os testes moleculares conseguem apontar apenas 25\% das alterações que levam ao distúrbio. Além disso, eventos que ocorrem durante a gestação, como a ingestão de alguns tipos de medicamentos, nutrientes e exposição a agentes tóxicos, também estão relacionados ao desenvolvimento desses transtornos ${ }^{3}$.

Os nutrientes ingeridos pela mãe durante a gravidez são, muitas vezes, indispensáveis para a gênese normal do embrião. Um importante micronutriente é uma das vitaminas do complexo B, a vitamina B9, que é hidrossolúvel e conhecida como folato ou ácido fólico, como é denominada a sua forma sintética. Tendo em vista que os mamíferos não são capazes do produzir essa vitamina, ela é obtida por meio da alimentação com a ingestão de folhas verdes, fígado e frutas cítricas, por exemplo 4 .

Na embriogênese, o ácido fólico tem importância no desenvolvimento do tubo neural, estrutura percursora do sistema nervoso central (SNC). De acordo com a Organização Mundial de Saúde, a quantidade de ácido fólico indicada, tanto antes quanto durante a gravidez, é de 0,4 mg $(=400 \mu \mathrm{g})$ uma vez ao dia. Essa suplementação previne diversos defeitos do tubo neural, como anencefalia, espinha bífida, entre outras, tendo em vista seu papel na proliferação celular e, consequentemente, no fechamento do tubo neural ${ }^{5}$.
Porém, o fechamento do tubo neural acontece ao mesmo tempo em que pode ocorrer, por exemplo, o desenvolvimento do TEA ${ }^{6}$. Tal fato foi mencionado em virtude das diversas pesquisas epidemiológicas que apontam aumento do referido transtorno nas duas últimas décadas, período de fortes campanhas da suplementação pelo ácido fólico.

Portanto, este trabalho visa, por meio de uma revisão de literatura mais recente, esclarecer a relação entre a ingestão do ácido fólico antes e/ou durante a gravidez e possível desenvolvimento do TEA.

\section{MÉTODOS}

O trabalho exposto apresenta como referência as diretrizes metodológicas para elaboração de revisão sistemática, estando de acordo com protocolo preestabelecido no manual Cochrane - versão 6 (setembro/2018).

\section{Estratégia de busca}

A estratégia de busca foi selecionar e avaliar artigos nos idiomas português e inglês indexados nas bases de dados Medical Publications - PubMed (http://www.pubmed.gov), Science Direct (www.sciencedirect.com), The Lancet (http:// www.thelancet.com), Latin American Literature in Health Sciences - Lilacs (http://bases.bireme.br), Scientific Electronic Library Online - SciELO (http://www.scielo.org), Scientific Acadêmico (http://scholar.google.com) e PubMed (https:// www.ncbi.nlm.nih.gov/pubmed), durante o período de novembro de 2017 a abril de 2018. Foram utilizados como descritores, tanto em português quanto em inglês: "Autismo", "Transtorno do Espectro Autista", "Folato", "Ácido Fólico", "Embriogênese", "Tubo Neural", "Concepção", "Gestação" e "Desenvolvimento do Sistema Nervoso Embrionário" combinados com booleano AND. A fim de aumentar a sensibilidade da busca, incluíram-se sinônimos, indexações e termos prévios ou derivações do assunto.

Nesta revisão foram incluídos artigos com dados sobre a reposição de micronutrientes durante a gestação, com enfoque na suplementação do ácido fólico, e que mostraram alguma relação, positiva ou negativa, entre o ácido fólico e o neurodesenvolvimento e o TEA. Quando necessário, foram também utilizadas citações clássicas de artigos mais antigos. Os dados foram extraídos de cada estudo de forma independente pelos autores. Os artigos que estavam de acordo com 
esses critérios foram categorizados em grupos para aumentar a acurácia da análise.

\section{Critérios de exclusão}

Durante a busca de informações, foram lidos dos artigos: título e resumo. Para os fins deste estudo, foram eliminados as duplicidades e os artigos que não se adequaram ao objetivo proposto. Excluíram-se também relatos de casos, revisões literárias e editoriais, bem como publicações anteriores a 2008.

\section{RESULTADOS}

Após a prospecção dos artigos científicos utilizando os descritores já mencionados para esta revisão, foram encontrados 174 artigos. Após a aplicação de critérios de exclusão, foi obtido o total de 87 artigos.

\section{Aspectos epidemiológicos do TEA}

Na década de 1960, do total de casos existentes, apenas 0,05\% era registrado 7 . Transtornos relacionados ao autismo eram considerados raros durante a década de 1980, com predominância aproximada de cinco em cada 10 mil pessoas ${ }^{8}$. Contudo, após o início dos anos 1990, houve aumento nos casos registrados de autismo. Assim, a média de prevalência mundial do autismo naquela década já atingia cerca de 1\% em crianças 9 .

No ano de 2010, o número de indivíduos diagnosticados com autismo chegava a cerca de 52 milhões de pessoas no mundo, sendo mais prevalente em indivíduos do sexo masculino do que no feminino, com uma proporção de quatro para um, respectivamente ${ }^{10,11}$.

No continente asiático, mais especificamente na Coreia do Sul, a predominância de 2,64\% casos de TEA foi registrada em crianças com idade entre 7 e 12 anos, em um período de quatro anos (2005-2009)'2. Nos Estados Unidos, em 2012, o Centro de Controle e Prevenção de Doenças estimou que cerca de 1,5\% de crianças com idade de 8 anos possuíam TEA ${ }^{13}$. Porém, foi registrado no período de 2011 a 2014 que a predominância de indivíduos com TEA seria de 2,2\% naqueles com idade de 3 a 17 anos $^{14}$. Já na Suécia, a porcentagem registrada em relação ao número de adolescentes com diagnóstico de TEA foi de $2,5 \%{ }^{15}$.

No Brasil, no ano de 2009, o número de indivíduos com diagnóstico de TEA estava estimado em $500 \mathrm{mil}^{16}$. Atualmente, apesar de haver poucos estudos epidemiológicos, acredita-se que existam cerca de 2 milhões de pessoas com autismo no Brasil ${ }^{17}$. Não existem estudos que tragam dados sobre a proporção das crianças que possuem o diagnóstico de TEA nas diferentes regiões do Brasil. Entre os trabalhos brasileiros que realizaram alguma análise epidemiológica, a amostra avaliada, na maioria dos casos, era pequena e/ou referente apenas a alguma cidade, sem grandes valores de generalizações. No entanto, foi encontrado um estudo que divergiu nesses aspectos. Essa pesquisa foi realizada no sul do Brasil, onde foram relatados 1.254 casos desse transtorno, com prevalência estimada em 3,85/10.000 habitantes e foi verificada uma razão de 2,2 casos do sexo masculino para cada caso do sexo feminino. O maior número de casos relatados estava na faixa de 5 a 9 anos de idade ${ }^{18}$.

\section{Sinais e sintomas do TEA}

De maneira geral, os primeiros sinais e sintomas do TEA surgem por volta dos 3 anos de idade. Porém, antes mesmo dessa idade, é possível perceber as alterações no comportamento. Em algumas situações, o TEA pode ser identificado com menos de 2 anos de idade; em outros casos, ele pode ser diagnosticado em idades mais tardias ${ }^{19}$.

A percepção desses sintomas pode estar relacionada com a gravidade com a qual o transtorno se manifesta. No caso de o transtorno afetar de forma mais grave o SNC, torna-se mais fácil identificá-lo mesmo em idade inferior aos 3 anos $^{20}$.

A percepção dos pais em relação aos sintomas de seus filhos é muito importante para que o TEA não seja diagnosticado tardiamente. Os sinais observados mais precocemente pelos genitores foram os de aspecto social, sendo identificadas as dificuldades de interagir socialmente, que incluem medo, ansiedade ou indiferença, por exemplo, nas interações sociais. Esses sinais podem tornar-se visíveis aos pais a partir dos seis primeiros meses de vida da criança21.

Apesar de os sintomas relacionados às interações sociais serem os identificados mais cedo ao longo do crescimento da criança, os danos no desenvolvimento da linguagem são os percebidos mais vezes pelos genitores. Sendo assim, o desenvolvimento da linguagem, juntamente com os comportamentos estereotipados e repetitivos, são os sinais que foram identificados entre o primeiro e o segundo ano de vida ${ }^{21}$. Além disso, logo nos três primeiros anos de vida, cerca de 1/5 das crianças identificadas em um banco de dados possuía regressão em suas habilidades de linguagem oral22.

Um ponto relevante é o fato de que determinadas características encontradas em bebês com TEA sofrem um declínio a partir do final do primeiro semestre de vida ${ }^{23}$. Algumas dessas características incluem a vocalização, o número de vezes em que o bebê olha diretamente para faces e o chamado sorriso social. Isso foi observado a partir de um estudo realizado pelo autor, fazendo uma comparação entre bebês com desenvolvimento típico e bebês que foram diagnosticados com TEA ao longo do crescimento.

Ainda, apesar da proporção entre indivíduos do sexo masculino e feminino ser de 4 para 1, respectivamente, no geral, as meninas possuem sintomas mais severos e Ql menor em relação aos meninos ${ }^{24}$. Porém, caso as crianças do sexo feminino possuam Ql mais elevado, elas podem desenvolver comportamento repetitivo menos intenso, além de serem capazes de desenvolver habilidades sociais ${ }^{25}$. 


\section{Diagnóstico clínico e tratamento do TEA}

O diagnóstico do TEA é bastante complexo e diversos fatores são levados em consideração pelo profissional de saúde responsável. É de extrema importância que, antes de ser feito o diagnóstico, um médico descarte outros transtornos psiquiátricos, como transtorno do apego reativo, esquizofrenia infantil, por exemplo, e transtornos de desenvolvimento, como os relacionados à linguagem. Um bom exemplo disso é que, apesar de haver semelhanças entre o TEA e a esquizofrenia infantil em relação às interações sociais e determinado padrão de pensamento, elas se diferem pelo fato de que é bastante raro crianças com TEA apresentarem alucinações e delírios, os quais são sintomas frequentes da esquizofrenia, como parte dos sinais clínicos observados ${ }^{26}$.

Após feito o diagnóstico clínico por meio da avaliação de um profissional médico especializado, o tratamento deverá ser realizado de acordo com o grau de severidade dos sintomas e a apresentação deles. Além disso, o tratamento é feito com diferentes abordagens e tipos de terapias ao mesmo tempo, por exemplo: terapias comportamentais, terapia para desenvolver habilidades sociais, fisioterapia, entre outras ${ }^{27}$.

Um dos mais importantes métodos de intervenção, o comportamental, vem sendo bastante utilizado ao longo dos $a_{n o s^{28}}$. Esse tipo de intervenção tem por característica uma estimulação individualizada, realizada por muitas horas semanais (de 15 a 40 horas), por pelo menos dois anos consecutivos, cujas áreas do desenvolvimento são envolvidas simultaneamente e que é fundamentada em princípios de Análise do Comportamento ${ }^{29}$.

Nesse método, tomando como base um trabalho desenvolvido em 198730, há o programa de Intervenção Precoce Intensiva Comportamental, o qual visa utilizar o tempo de 40 horas semanais para que habilidades das mais simples às mais complexas possam ser ensinadas e, assim, desenvolvidas pelas crianças que possuem TEA. Além do mais, essa técnica é bastante útil quando comportamentos inadequados afetam a disposição de tratamentos mais amplos. Dessa forma, é feita uma análise do perfil e do comportamento do paciente para que as técnicas de tratamento comportamental sejam aplicadas, trazendo melhores resultados ${ }^{26}$.

Os estudos atuais a respeito dos efeitos de um modelo de Intervenção Comportamental Intensiva aplicado ao tratamento de crianças com autismo continuam trazendo resultados similares aos que foram alcançados no estudo inicial ${ }^{30}$, no entanto utilizando educadores diferentes (estudantes, profissionais e familiares) e contextos múltiplos (instituições especializadas, escolas e a residência das crianças) ${ }^{29}$. As pesquisas indicaram, no geral, melhora no desenvolvimento dos participantes após realizarem esse tipo de intervenção.

Outra abordagem para o tratamento de indivíduos com TEA é o método educacional. Esse método visa ensinar, de forma específica e individual, as crianças com TEA, baseando-se nos pontos fortes e fracos delas, além de contar com o apoio dos pais, cujo suporte tem papel importante para que haja eficácia nesse tratamento. Ainda nesse método, busca-se melhorar a maneira da criança de se comunicar, seja verbalmente ou não, além de melhorar as capacidades motoras, sociais e comportamentais ${ }^{26}$.

O uso de tratamento por meio da comunicação também é outra alternativa ${ }^{26}$. Esse tratamento envolve o desenvolvimento da linguagem e da comunicação, auxiliando crianças a utilizarem comunicação verbal ou, naquelas que não a possuem, a se comunicarem de maneira não verbal (linguagem de sinais, comunicação por imagens ou quadros).

O TEA muitas vezes está acompanhado de distúrbios emocionais e comportamentais, incluindo ansiedade, irritabilidade, humor lábil, desatenção, hiperatividade e problemas de sono, que podem levar a comprometimento funcional e carga emocional e econômica significativa para os cuidadores. O uso de fármacos para o tratamento é válido em alguns desses casos e inclui antipsicóticos, como risperidona e aripiprazol, que são eficazes na diminuição da irritabilidade de pacientes com TEA ${ }^{27}$. O uso desses fármacos pode elevar as chances de melhoras relacionadas às abordagens comportamentais e educacionais ${ }^{26}$.

\section{Fatores que desencadeiam o TEA}

É bastante complexo relacionar causas que desencadeiam o TEA em razão da heterogeneidade fenotípica entre as crianças que o possuem. No entanto, os fatores genéticos mostraram-se importantes para os estudos etiológicos do referido transtorno. Tal constatação decorreu de pesquisas que observaram maior frequência do TEA entre irmãos, principalmente em casos de irmãos gêmeos ${ }^{26,31}$.

As causas desse transtorno podem estar fortemente relacionadas a fatores presentes no ambiente compartilhado entre os irmãos, o que, em seu ponto de vista, poderia ser mais importante do que os fatores hereditários. Contudo, os fatores genéticos devem ser mais creditados sobre o desenvolvimento do TEA em relação aos ambientes compartilhados e fatores não hereditários, embora não se deva excluir a possibilidade desses últimos acontecerem ${ }^{32}$.

Apesar de, na maioria dos casos, o TEA não ser causado por uma mutação genética específica, alguns autores afirmam que o risco pode ser elevado em razão de mutações num um único gene ${ }^{34}$. Um exemplo disso é a associação entre mutações no gene fragile $X$ mental retardation 1 (FMR1), causadora da síndrome do X frágil, com a presença do TEA em alguns casos $^{35}$.

Ainda levando em consideração a associação do TEA com outras doenças relacionadas a mutações, é importante investigar se há mutações no gene relacionado a síndrome de Rett, o gene $M E C P 2$, principalmente em razão de pacientes com TEA do sexo feminino com deficiência intelectual grave terem chance de apresentar mutações deletérias nele ${ }^{36}$. Por fim, mutações nos genes de novo, os quais são responsáveis 
por determinadas funções no sistema nervoso como motilidade neuronal e desenvolvimento sináptico ${ }^{37}$, podem também estar associadas a alguns casos de TEA ${ }^{38}$, devido à variação no número de cópias do gene $(C N V)^{39}$. Sendo assim, é possível que o TEA esteja ligado ao funcionamento defeituoso das sinapses e de processos neuronais, como sugerido em um editorial ${ }^{40}$ e suportando em um artigo original ${ }^{37}$.

Já em termos de fatores ambientais ${ }^{41}$, perturbações provenientes do ambiente e ocasionadas durante o período fetal podem atingir o neurodesenvolvimento do feto, sem que haja relação com os genes. Entre esses fatores ambientais, alguns componentes químicos possuem a capacidade de atravessar as barreiras placentária e hematoencefálica do embrião/feto, fazendo com que haja interferência no desenvolvimento do sistema nervoso, por meio da interrupção de vias hormonais ou mediante a ação em vias inflamatórias ${ }^{42}$. Estudos feitos em Taiwan apontam que alguns compostos poluentes, como ozônio $\left(\mathrm{O}_{3}\right)$ e óxido nítrico $\left(\mathrm{NO}_{2}\right)$, podem ter relação com o aumento da incidência do TEA nesse local ${ }^{43}$.

Ainda, no estado da Califórnia, estudos apontam que o contato com o $\mathrm{NO}_{2}$ pode, também, estar envolvido com o aumento da decorrência do TEA na população local. Todavia, estudos realizados no continente europeu apontam que não há relação entre o desenvolvimento do TEA com a emissão de $\mathrm{NO}_{2}{ }^{44}$. Porém, os resultados das pesquisas podem depender de fatores sociais, do organismo e do nível de exposição da população aos poluentes ${ }^{42}$.

A saúde da mãe também tem influência no desenvolvimento do TEA, pois a pré-eclâmpsia está implicada numa frequência 32\% maior do número de casos com o referido transtorno quando comparada ao nascimento de crianças que não foram expostas a ela ${ }^{45}$. Ademais, as condições em que se encontra o metabolismo da mãe durante a gravidez podem ser relacionadas não apenas ao TEA, mas também a atrasos no desenvolvimento ${ }^{46}$.

Outro fator importante que pode influenciar no aumento do risco de desenvolver TEA é a ingestão de determinados fármacos pela mãe. A ingestão de ácido valproico, um medicamento utilizado como estabilizante de humor e anticonvulsivante, durante a gestação pode afetar o neurodesenvolvimento do feto, aumentando o risco de TEA ${ }^{47}$.

Num estudo mais antigo, foi apontado que o efeito teratogênico da talidomida não só está relacionado com as malformações nos membros, mas também pode ser considerado um dos fatores que aumenta o risco de desenvolver o referido transtorno ${ }^{48}$.

Estudos mais recentes ${ }^{42}$ têm apontado outros medicamentos pré-natais, que incluem antidepressivos (particularmente inibidores seletivos da recaptação da serotonina - ISRS), antiasmáticos (sobretudo os agonistas do receptor adrenérgico $\beta$-2) e antiepiléticos. Embora consideravelmente diferentes em atividade, esses medicamentos têm a capacidade de atravessar a placenta e a barreira hematoencefálica, além de também poderem ser transferidos para a criança por meio do leite materno, e evidências de modelos animais apoiam os efeitos neurológicos na prole exposta no pré-natal.

\section{Metabolismo do ácido fólico}

O folato é um poliglutamato que foi descoberto pela hematologista Lucy Wills, no ano de $1931^{49}$, sendo a forma sintética conhecida como ácido fólico produzida alguns anos depois, na década de 194050. O ácido fólico (N-[4-([2-amino-4-hidroxi-6-pteridil)-metil]-amino)-benzoil]-glutâmico), ou ácido pteroilglutâmico, é composto de um anel aromático de pteridina preso a um ácido p-aminobenzoico por um grupo metileno, além de um resíduo de glutamato na forma de ácido glutâmico ${ }^{51}$. O ácido fólico difere do folato quanto à presença de um próton a mais e por ser mais estável quando adicionado aos alimentos e comprimidos ${ }^{52}$.

Quando o ácido fólico é ingerido, a enzima di-hidrofolato redutase o reduz para uma forma bioativa natural denominada de tetra-hidrofolato (THF). Ainda, há a adição de uma unidade de carbono e as reduções, o THF é transformado em 5-metiltetra-hidrofolato (5-MeTHF) monoglutamato, a qual é a forma circulante do folato ${ }^{52}$.

O ácido fólico é absorvido pelo intestino mais rapidamente que o folato, considerando que ele é estruturado como monoglutamato. Tal fato ocorre porque o folato (presente em $90 \%$ dos alimentos) está na forma de poliglutamato ${ }^{53}$, apresentando uma "cauda" com mais três resíduos de glutamato, portanto ele não consegue atravessar a membrana celular ${ }^{51}$.

Para que haja a absorção do folato, uma enzima conhecida como glutamato carboxipeptidase II, a qual se encontra na borda em escova do epitélio intestinal dos seres humanos, age nele transformando-o em monoglutamato ${ }^{53}$. É importante ressaltar que é necessária a ingestão tanto da forma natural como sintética da referida vitamina para que seja atendida a quantidade necessária recomendada por dia ${ }^{49}$.

$\mathrm{Na}$ corrente sanguínea, o folato circula na forma de monoglutamato, contudo, no interior das células, a forma predominante dele é poliglutamato, para que não ocorra perda do folato para o meio extracelular ${ }^{54}$. A enzima responsável por adicionar resíduos de glutamato à forma simples do folato, transformando-o em poliglutamato, é a folipoliglutamato sintase (FPGS). Os autores também afirmam que o folato tem uma participação especial em reações de metilação, já que ele participa da síntese do cofator enzimático S-adenosilmetionina, responsável pela doação de grupos metil em metilações.

O estado do folato pode ser prejudicado no caso de polimorfismos atingirem alguns genes relacionados ao seu metabolismo. Essas alterações podem desencadear alguns tipos de câncer e doenças cardiovasculares. Assim, tendo em vista que folato é responsável por transportar unidades de um carbono, as quais fazem parte de vários processos re- 
gulatórios e metabólicos, a ingestão insuficiente dele pode comprometer esses processos. Um exemplo desses são as reações de metilação. Quando o corpo apresenta uma quantidade baixa de folato, pode ocorrer queda em um dos componentes importantes para essas reações: grupamentos de um carbono. Isso pode levar ao acúmulo do aminoácido homocisteína ${ }^{54}$.

A homocisteína é considerada um fator de risco para o desenvolvimento da doença arterial coronariana ${ }^{55}$. Além disso, os níveis elevados de homocisteína no sangue de uma gestante podem promover maior risco de a criança desenvolver defeitos no fechamento do tubo neural56.

\section{O ácido fólico na embriogênese}

O folato é uma vitamina que possui papel importantíssimo na formação do DNA e RNA, bem como na multiplicação celular, sendo assim, é indispensável para o desenvolvimento do feto. Além disso, ele atua em três importantes tipos de crescimento: eritrocitário, uterino e placentário. O folato também é necessário para o crescimento durante o período pré-natal e pós-natal, na lactação, na formação de anticorpos e como coenzima no metabolismo de aminoácidos e síntese de purinas e pirimidinas, assim como na síntese proteica. Na sua insuficiência, podem ocorrer alterações na produção de DNA e, consequentemente, alterações cromossômicas ${ }^{57-59}$.

Como citado anteriormente, o ácido fólico faz parte de processos de metilação do DNA, considerando que ele está ligado ao fornecimento de grupos metil. Esses processos são indispensáveis durante o desenvolvimento embrionário ${ }^{60}$, sugerindo que os padrões de metilação nesse período podem ser afetados pelo ácido fólico, sendo esse um dos exemplos de processo que gera efeitos que se perduram ao longo da vida do indivíduo ${ }^{61}$.

Outra importância dessa vitamina é em relação ao crescimento da circunferência da cabeça do feto. Do segundo ao terceiro trimestre de gestação, a rapidez com a qual a cabeça do feto cresce tem ligação com a concentração de folato no sangue da mãe $e^{62}$. No entanto, os autores afirmam ainda que, após o nascimento da criança, não há crescimento da circunferência da cabeça relacionado com o ácido fólico.

Uma das mais relevantes e citadas participações do ácido fólico na embriogênese é sua importância para o fechamento do tubo neural. A ingestão dessa vitamina deve ser iniciada um mês antes da concepção até os três primeiros meses dela, de acordo com o Centro de Controle e Prevenção de Doenças dos Estados Unidos ${ }^{63}$. Estudos feitos no Canadá também relatam essa importância. Por exemplo, para muIheres e seus parceiros com histórico familiar de baixo risco de desenvolvimento de defeitos do tubo neural, recomenda-se a ingestão diária de 0,4 mg $(400 \mu \mathrm{g})$ de ácido fólico de dois a três meses antes da concepção, continuando durante toda a gestação, se estendendo até seis semanas após o parto ou ao longo do período de amamentação. Já para mulheres com alto risco, é recomendada a ingestão, no mínimo, três meses antes da concepção, de $4 \mathrm{mg}(4000 \mu \mathrm{g})$ de ácido fólico. Essa suplementação deve ser continuada até a $12^{a}$ semana de gestação e, passando desse período, a ingestão deve ser continuada até o parto, mas em menor dose: de 0,4 mg $(400 \mu \mathrm{g})$ a $1 \mathrm{mg}(1000 \mu \mathrm{g})$ por dia, e deve se prolongar, também, até seis semanas após o parto ou durante todo o período de amamentação ${ }^{64}$.

A ingestão correta do folato pode reduzir em até $70 \%$ a chance de o embrião desenvolver defeitos do tubo neural, os quais podem ocorrer em 1 a cada 1.000 gestações ${ }^{65}$. Apesar do conhecimento sobre a importância do ácido fólico para o desenvolvimento do SNC ${ }^{52}$, não se sabe ao certo como o ácido fólico age nas células embrionárias para a formação do tubo neural ${ }^{65}$.

Diferentes estudos publicados mostraram que a suplementação com ácido fólico promove reduções significativas na prevalência de defeitos do tubo neural, sendo comprovado o seu benefício em termos de proteção em diversos países e regiões estudadas, com os resultados variando entre 16\% e 78\%. Embora a fortificação obrigatória ocorra em 40 países, como Canadá e Brasil66, por exemplo, a avaliação dos resultados dessa estratégia foram feitas em apenas cinco. Nos Estados Unidos, dados obtidos a partir de monitoramento dos nascidos vivos apontam que o ácido fólico tem o poder de prevenir outros defeitos congênitos, como a fissura do palato e labial, além de evitar defeitos nos membros inferiores e posteriores ${ }^{67}$.

No entanto, estudos mais antigos apontam que a metilação no gene receptor $\mathrm{A}$ do fator de crescimento de plaquetas (PDGFRA) pode gerar defeitos do tubo neural ${ }^{68,69}$, levando em consideração o fato de que o metabolismo do ácido fólico está ligado aos processos de metilação no DNA e, ao mesmo tempo, é responsável pelo fechamento do tubo neural.

De maneira controversa ${ }^{70}$, o ácido fólico também pode evitar defeitos do tubo neural relacionados com substâncias que são antagonistas dele. Isso significa que medicamentos para epilepsia como carbamazepina, por exemplo, podem duplicar as chances de a criança desenvolver defeitos do tubo neural, tendo em vista que trabalham como antagonistas do ácido fólico. Contudo, em mães que necessitam tomar esse medicamento, a suplementação da dieta com ácido fólico pode diminuir os riscos de defeitos do tubo neural.

Uma pesquisa $a^{71}$ sobre definição do limite da quantidade de ácido fólico ingerida pela gestante aponta que essa limitação pode ser considerada um empecilho para que os números de crianças nascidas com defeitos do tubo neural em diversos países diminuam, principalmente naqueles em que a fortificação de alimentos com essa vitamina não é obrigatória. Inclusive, os autores atentam para o fato de que, se não houvesse esse limite, que é de $1 \mathrm{mg}$ de ácido fólico por dia, os países que ainda não o adicionam aos alimentos poderão passar a fazê-lo. 
Além dos defeitos do tubo neural, em estudos com ratos, segundo uma revisão sistemática ${ }^{72}$, afirmou-se que pode ocorrer hipometilação de genes no fígado dos descendentes caso a dieta da mãe durante a gestação tenha sido privada de proteína e ácido fólico. Porém, os autores afirmam que, com a ingestão de grandes quantidades de ácido fólico, mesmo que a dieta da mãe esteja baseada em baixas quantidades de proteína, se pode evitar a hipometilação desses genes, diminuindo a chance de ocorrerem mutações nas células do fígado.

\section{Relação entre o uso de ácido fólico e o desenvolvimento do TEA}

Várias pesquisas ${ }^{73-80}$ relatam sobre a importância do ácido fólico durante o desenvolvimento do SNC, destacando sua ação no fechamento do tubo neural, mas não encontram evidências suficientes para comprovar alguma relação da suplementação de ácido fólico antes e durante a gravidez com o desenvolvimento do TEA. Contudo, poucos estudos recentes já relatam uma possível associação.

Um estudo ${ }^{81}$ aponta que o ácido fólico pode ser um fator ambiental que desencadeia o TEA, se levados em consideração o nível de folato na corrente sanguínea de crianças com traços autistas e a ingestão da sua forma sintética pela gestante. Além disso, os autores também apontam para o fato de que os níveis de homocisteína encontrado em amostras de sangue dessas crianças são altos.

De forma contraditória, no estado da Califórnia, num estudo de caso ${ }^{82}$, os autores afirmaram que a dieta da gestante suplementada com ácido fólico, 12 semanas antes da gravidez e até quatro semanas do período gestacional, auxiliou na redução dos riscos de a criança desenvolver TEA. Um estudo semelhante foi desenvolvido na Noruega. A suplementação com essa vitamina feita quatro semanas antes da concepção até a oitava semana de gravidez também mostrou que há redução nos riscos de desenvolvimento de TEA ${ }^{83}$. Por outro lado, em um estudo realizado na Dinamarca, não foi apresentada redução significativa nos riscos do desenvolvimento do transtorno após a ingestão do ácido fólico em período anterior e posterior à concepção ${ }^{84}$.

Ainda, um estudo recente ${ }^{85}$ aponta que existe e permanece a redução do risco de desenvolvimento do TEA pela criança quando, durante o período gestacional, há a suplementação de ácido fólico e multivitamínicos, principalmente se mãe apresentar deficiência de vitaminas. Contudo, os mesmos autores apontaram que não foi observada redução do risco quando mães com deficiência de vitaminas fizeram a suplementação anteriormente à concepção, e não durante a gestação.

Um trabalho realizado com filhos de mães em uso de medicamentos antiepiléticos ${ }^{86}$ investigou não só a associação dos fármacos antiepiléticos e suas concentrações, como também avaliou a influência do uso de maconha e da suplementação de ácido fólico durante a gestação com o desenvolvimento do autismo. Eles relatam que alguns trabalhos utilizados na sua pesquisa especulavam que o aumento do uso de folato materno poderia estar associado ao aumento da prevalência de TEA. No entanto, os dados deles contradizem isso e, de fato, destacam a importância da suplementação de ácido fólico em mulheres com epilepsia, com uma associação entre escores elevados de CARS (Escala de Classificação do Autismo na Infância) em crianças cujas mães não relataram a suplementação de ácido fólico no primeiro trimestre.

Uma revisão sistemática e metanálise ${ }^{87}$ de 2018 revelou que a suplementação pré-natal de ácido fólico não apresentou associação significativamente maior com o desempenho mental ou desenvolvimento motor em qualquer dose, quando comparado a menos de $400 \mu \mathrm{g}$ por dia. No entanto, foi observada associação estatisticamente significativa entre uma ingestão inferior a $400 \mu \mathrm{g}$ por dia e uma ingestão de 400 a $999 \mu \mathrm{g}$ por dia, com melhores escores médios de desenvolvimento mental associados a maior ingestão. Além disso, esse mesmo trabalho mostrou que a suplementação pré-natal de ácido fólico, em comparação com nenhuma suplementação, reduziu significativamente (cerca de 58\%) o risco associado de TEA em crianças.

No caso de mães sem a deficiência de vitamina, a suplementação de ácido fólico e multivitamínicos reduziu os riscos de a criança desenvolver TEA. Esse resultado foi observado, inclusive, no caso de a mulher iniciar a suplementação dois anos antes do momento em que deseja engravidar. Porém, os autores afirmam que é necessário o desenvolvimento de pesquisas no futuro para averiguar se essa redução se deve, de fato, à ingestão do ácido fólico e outras vitaminas ${ }^{85}$.

No estudo ${ }^{82}$ desenvolvido no período de 2003 a 2009, os autores observaram que o gene da enzima metilenotetra-hidrofolato redutase (MTHFR) pode apresentar a mutação c677t. Essa mutação é um polimorfismo que está associado ao aumento da homocisteína. Assim, os autores afirmam que a ingestão do ácido fólico precisa ser elevada para que haja o desenvolvimento adequado do sistema nervoso. Dessa forma, o resultado da pesquisa aponta que a ingestão de uma média maior do que $0,6 \mathrm{mg}(=600 \mu \mathrm{g})$ por dia reduziu mais o risco de desenvolvimento de TEA do que a média abaixo desse valor. A tabela 1 traz uma síntese dos artigos abordados neste tópico.

\section{DISCUSSÃO}

O TEA engloba diferentes condições marcadas por alterações do desenvolvimento neurológico com três características fundamentais - dificuldade de comunicação por deficiência no domínio da linguagem e no uso da imaginação 
para lidar com jogos simbólicos, dificuldade de socialização e padrão de comportamento restritivo e repetitivo - que podem manifestar-se em conjunto ou isoladamente ${ }^{7}$. É um distúrbio neurológico complexo que afeta milhões de pessoas no mundo. Admite-se que o aumento observado na frequência do TEA se deva, também, a uma melhoria no reconhecimento e detecção, principalmente, dos casos sem deficiência mental ${ }^{42}$.

Algumas publicações recentes têm afirmado que o suplemento do ácido fólico antes da concepção e durante a gestação pode ser um dos fatores desencadeantes do TEA. Essa possível relação pode ter surgido devido a função do ácido fólico nos processos de metilação do DNA, servindo como depósitos de unidades de carbono. Essas reações fazem parte de vários processos regulatórios e metabólicos indispensáveis no desenvolvimento embriológico. Dessa forma, os níveis de folato poderiam interferir nesses processos, produzindo efeitos que perduram por toda a vida do indivíduo. No entanto, os resultados são controversos e inconsistentes.

Tabela 1. Resumo dos estudos que abordam o ácido fólico e o possível desenvolvimento de TEA

\begin{tabular}{|c|c|c|}
\hline Autor & Ano & Metodologia \\
\hline $\begin{array}{l}\text { Schmidt } \\
\text { et al. }\end{array}$ & 2012 & $\begin{array}{l}\text { As famílias inscritas no estudo, de } 2003 \text { a } \\
2009 \text {, foram incluídas se seus filhos tivessem } \\
\text { diagnóstico de TEA ( } n=429 \text { ), atraso no de- } \\
\text { senvolvimento ( } n=130 \text { ) ou desenvolvimen- } \\
\text { to típico ( } n=278 \text { ). Dados sobre a ingestão } \\
\text { de multivitaminas, vitaminas pré-natais, } \\
\text { vitaminas específicas do ácido fólico, cereais } \\
\text { e outros suplementos foram coletados por } \\
\text { meio de entrevistas. Esses dados incluíam in- } \\
\text { formações sobre se cada item foi ou não con- } \\
\text { sumido; e se sim, qual marca e dose, durante } \\
\text { quais meses de um período de índice (come- } \\
\text { çando três meses antes e durante todo mês } \\
\text { da gravidez) e com que frequência o item foi } \\
\text { consumido. A partir dessas informações, foi } \\
\text { calculado um valor da ingestão de ácido fóli- } \\
\text { co com base na marca, dose e frequência de } \\
\text { consumo de cada produto e somado ao valor } \\
\text { total de cada mês para cada mulher. }\end{array}$ \\
\hline
\end{tabular}

Al-Farsi 20130 estudo incluiu 80 participantes $(40$ com et al. TEA e 40 controles). A ingestão retrospectiva de folato e vitamina B12 foi verificada usando o Reduced Dietary Questionnaire of Block, que é uma ferramenta semiquantitativa para medir a frequência de ingestão de alimentos. Amostras de sangue foram coletadas de cada um dos 40 casos e 40 controles pareados por idade, sexo e peso para estimar os níveis de folato sérico e vitamina B12. Os valores de corte foram de 3 a $20 \mathrm{ng} / \mathrm{mL}$ para folato e de 250 a $1.250 \mathrm{ng} / \mathrm{mL}$ para vitamina B12.

Surén $\quad 2013$ A amostra do estudo de 85.176 crianças foi et al. extraída do Estudo de Coorte Norueguês de Base Mãe e Filho (MoBa) de base populacional. A exposição de interesse primário foi 0 uso de ácido fólico de 4 semanas antes a 8 semanas após 0 início da gravidez, definido como o primeiro dia do último período menstrual antes da concepção.

2014 A literatura foi estudada com a ajuda de Medline, Cochrane, Web of Science e ScienceDirect.
Comparadas com o grupo controle, as mães das participantes do grupo caso tenderam a ter maiores taxas de analfabetismo e suplementação de ácido fólico durante a gravidez e maior consumo de farinha e pão fortificados.

Nas crianças cujas mães usavam ácido fólico, 0,10\% apresentavam TEA, em comparação com $0,21 \%$ naquelas não expostas ao ácido fólico.

Estudos recentes indicam que existe uma causa genética subjacente em $35 \%$ a $60 \%$ dos casos de TEA. Os fatores ambientais desempenham um papel maior do que se pensava anteriormente e desencadeiam o desenvolvimento de TEA em pessoas com vulnerabilidade genética. Não só existem evidências de fatores de risco para TEA, mas também há evidências de que certos fatores protegem, por exemplo, 0 uso de ácido fólico antes e durante a gravidez.
Conclusões

0 ácido fólico pode ser um fator ambiental que desencadeia 0 TEA, se levado em consideração 0 nível de folato na corrente sanguínea de crianças com traços autistas e a ingestão da sua forma sintética pela gestante. Além disso, os autores também apontam para o fato de que os níveis de homocisteína encontrados em amostras de sangue dessas crianças são altos.

0 ácido fólico pode ser um fator ambiental que desencadeia 0 TEA, se levados em consideração o nível de folato na corrente sanguínea de crianças com traços autistas e a ingestão da sua forma sintética pela gestante. Além disso, os autores também apontam para o fato de que os níveis de homocisteína encontrados em amostras de sangue dessas crianças são altos.

0 uso de suplementos de ácido fólico pré-nata na época da concepção foi associado a um menor risco de distúrbio autista na coorte MoBa. Embora esses achados não possam estabelecer causalidade, eles apoiam a suplementação pré-natal de ácido fólico.

0 TEA provavelmente está relacionado a uma combinação de mutações genéticas e fatores ambientais e às interações entre os dois. Mais pesquisas são necessárias sobre as causas genéticas e ambientais do TEA. 


\begin{tabular}{lcll}
\hline Autor & Ano & \multicolumn{1}{c}{ Metodologia } & \multicolumn{1}{c}{ Principais evidências encontradas } \\
\hline Neggers & 2014 & Revisão da literatura & Há evidências de que a suplementação materna de ácido fólico du- \\
& & rante a gravidez pode reduzir o risco de outros distúrbios do neuro- \\
& desenvolvimento em crianças. 0 envolvimento da alteração no ci- \\
& clo do folato-metionina pode desempenhar um papel fundamental \\
& na etiologia do autismo. 0 folato desempenha vários papéis-chave \\
& na manutenção e reparo do genoma, regulação da expressão gêni- \\
& ca, metabolismo de aminoácidos e formação de mielina. 0 autismo \\
& é um distúrbio do desenvolvimento neurológico que se origina \\
& potencialmente durante o início da gravidez, quando se sabe que \\
& o folato é crítico.
\end{tabular}

Lyall et al. 2014 Revisão das evidências de fatores preconcepção e/ou fatores pré-natais que foram associados, em alguns estudos, ao TEA, incluindo nutrição, uso de substâncias e exposição a agentes ambientais. A revisão restringiu-se a estudos em humanos com pelo menos 50 casos de TEA, com um grupo de comparação válido, realizado na última década e com foco no estilo de vida materno ou em produtos químicos ambientais.

Braun 2014 Avaliamos apenas 0 uso pré-natal de vitamiet al. nas durante os últimos 6 meses de gravidez, e não durante o período periconcepcional.

Neggers 2014 Revisão da literatura

Vilbiss 2015 Revisão da literatura

et al.

Wood

et al.

2015 Participaram 105 crianças australianas de 6 a 8 anos que foram recrutadas pelo Registro Australiano de Gravidez para Mulheres em uso de medicamentos antiepiléticos. Epilepsia materna, gravidez e histórico médico foram obtidos prospectivamente. As características do autismo foram avaliadas usando a Escala de Classificação do Autismo na Infância (CARS).

Virk et al. 2016 Informações sobre 0 diagnóstico do transtorno do espectro do autismo foram obtidas no National Hospital Register e no Central Psychiatric Register. Foram estimadas taxas de risco para distúrbios do espectro do autismo em crianças cujas mães tomaram suplementos de folato ou multivitamínicos de 4 semanas antes do último período menstrual até 8 semanas após 0 último período menstrual em três períodos de 4 semanas.
Maior ingestão materna de certos nutrientes e suplementos tem sido associada à redução do risco de TEA, com as evidências mais fortes para suplementos periconcepcionais de ácido fólico.

As crianças nascidas de mulheres que tomavam vitaminas pré-natais semanalmente/diariamente apresentaram menores chances de escores SRS clinicamente elevados do que aquelas que raramente/nunca os tomaram. As concentrações de folato no sangue materno não foram associadas aos escores da SRS.

Resultados de vários estudos são encorajadores, mas é muito cedo para dizer que o uso universal periconcepcional do ácido fólico pode reduzir a incidência de TEA resultante do metabolismo anormal da folato-metionina. Alguns estudos epigenéticos muito recentes em gêmeos monozigóticos fornecem suporte para o papel potencial da fólico no TEA. Além disso, é difícil isolar o nível de ingestão materna de ácido fólico que pode resultar em causa suficiente para contribuir para o desenvolvimento de várias formas de autismo.

Dados de animais e humanos indicam que o status materno do folato pode ser um fator de risco biologicamente plausível para TEA. A ingestão insuficiente de folato pode resultar em hipometilação do DNA, e a hipometilação está associada ao neurodesenvolvimento. No entanto, 0 peso das evidências sobre o papel do status materno do folato e o desenvolvimento de TEA está longe de ser inequívoco. Dadas as suas limitaçōes no desenho do estudo, especialmente no que diz respeito ao tempo de exposição e ao potencial de confusão por outras vitaminas, os ensaios e estudos randomizados de biomarcadores de folato materno fornecem poucas informações sobre o papel potencial da FA como um fator protetor contra ca-

As comparações de grupo mostraram que, em relação com mães de crianças sem traços de autismo, as mães de crianças com traços de autismo eram mais propensas a ter uma ou mais crises durante a gravidez, mais propensas a usar maconha durante a gravidez e menor probabilidade de ter tomado suplementos de ácido fólico no primeiro trimestre.

Não se encontrou associação entre ingestão precoce de folato ou multivitamínico para transtorno do espectro do autismo, transtorno autista, síndrome de Asperger ou distúrbio generalizado do desenvolvimento, em comparação com as mulheres que relataram não usar suplementos no mesmo período. metilação do DNA por meio de uma alta ingestão materna de ácido racterísticas de ASD.
Conclusōes

A maioria das evidências avaliadas sugere uma ligação entre a ingestão pobre de ácido fólico materno e/ou os níveis de ácido fólico durante a primeira infância e os distúrbios relacionados ao autismo. Mas ainda são necessários mais estudos para tornar essa evidência indiscutível.

São necessários mais trabalhos para examinar gorduras, vitaminas e outros nutrientes maternos, bem como produtos químicos e pesticidas desreguladores endócrinos, em associação com 0 TEA, dadas a plausibilidade biológica sólida e as evidências sobre outros déficits no desenvolvimento neurológico.

Há importância do folato durante 0 desenvolvimento do SNC, mas não encontram evidência suficiente para comprovar alguma relação entre a suplementação de ácido fólico antes e durante a gravidez com o desenvolvimento do TEA.

A suplementação perinatal de ácido fólico como forma de impedir 0 autismo ainda é uma questão em aberto.

Como a evidência existente é inconclusiva, mais pesquisas ainda precisam ser conduzidas para verificar essa hipótese.

A suplementação com ácido fólico no primeiro trimestre e 0 uso de maconha mostraram-se como preditores significativos dos escores da CARS.

Não foi encontrada nenhuma evidência para corroborar relatos anteriores de um risco reduzido de distúrbios do espectro do autismo em filhos de mulheres que usam suplementos de ácido fólico no início da gravidez. 


\begin{tabular}{|c|c|c|c|c|}
\hline Autor & Ano & Metodologia & Principais evidências encontradas & Conclusões \\
\hline $\begin{array}{l}\text { Castro } \\
\text { etal. }\end{array}$ & 2016 & $\begin{array}{l}\text { Revisão literária de estudos escritos em in- } \\
\text { glês que avaliaram a relação entre autismo e } \\
\text { folato, contidos no banco de dados Medline. }\end{array}$ & $\begin{array}{l}\text { Em relação à questão principal do trabalho, a saber, o efeito da } \\
\text { suplementação com ácido fólico, principalmente na gravidez, os } \\
\text { poucos e contraditórios estudos apresentam conclusões inconsis- } \\
\text { tentes. }\end{array}$ & $\begin{array}{l}\text { Embora alguns estudos tenham relatado níveis } \\
\text { mais baixos de folato em pacientes com TEA, os } \\
\text { efeitos de intervenções que aumentam o folato nos } \\
\text { sintomas clínicos ainda não foram confirmados. }\end{array}$ \\
\hline $\begin{array}{l}\text { Strøm } \\
\text { etal. }\end{array}$ & 2018 & $\begin{array}{l}\text { Foram incluídos todos os filhos únicos nasci- } \\
\text { dos vivos ( } \mathrm{n}=92.676 \text { ). Excluíram-se crianças } \\
\text { com peso de nascimento }<2.500 \mathrm{~g} \text { ou idade } \\
\text { gestacional <32 semanas ( } \mathrm{n}=89.293 \text { ), ou } \\
\text { faltando informações sobre } 0 \text { uso de suple- } \\
\text { mentos, deixando } 87.210 \text { pares de mãe e } \\
\text { filho para as análises. Foram definidas "usu- } \\
\text { árias" como mulheres que relataram tomar } \\
\text { um suplemento contendo ácido fólico duran- } \\
\text { te as semanas - } 4 \text { a - } 1,1 \text { a } 4 \text { ou } 5 \text { a } 8 \text {. Na aná- } \\
\text { lise de sensibilidade, definiram-se "usuárias } \\
\text { consistentes" como aquelas que haviam to- } \\
\text { mado suplementos com ácido fólico durante } \\
\text { todo o período de } 4 \text { a } 8 \text { semanas de gestação. } \\
\text { Além disso, nas análises de sensibilidade, } \\
\text { foram testadas uma associação de vitamina } \\
\text { B12 periconcepcional com TEA, bem como } \\
\text { uma interação entre B12 periconcepcional e } \\
\text { suplementação de ácido fólico em associação } \\
\text { com TEA. }\end{array}$ & $\begin{array}{l}\text { Não houve associação detectável entre a suplementação materna } \\
\text { de ácido fólico no período periconcepcional e o TEA dos filhos. }\end{array}$ & $\begin{array}{l}\text { Não foi apresentada redução significativa nos } \\
\text { riscos do desenvolvimento do transtorno após } \\
\text { a ingestão do ácido fólico em período anterior e } \\
\text { posterior à concepção. }\end{array}$ \\
\hline $\begin{array}{l}\text { Levine } \\
\text { et al. }\end{array}$ & 2018 & $\begin{array}{l}\text { Estudo de coorte de controle de caso de } \\
45.300 \text { crianças israelenses nascidas entre } 1 \\
\text { de janeiro de } 2003 \text { e } 31 \text { de dezembro de } 2007 \text {, } \\
\text { acompanhadas desde o nascimento até } 26 \text { de } \\
\text { janeiro de } 2015 \text { para o risco de TEA. Os casos } \\
\text { foram todas crianças diagnosticadas com TEA } \\
\text { e os controles foram uma amostra aleatória } \\
\text { de } 33 \% \text { de todas as crianças nascidas vivas. }\end{array}$ & $\begin{array}{l}\text { Foi observada redução do risco de desenvolvimento de TEA em } \\
\text { crianças cujas mães que apresentavam deficiência em ácido fóli- } \\
\text { co realizaram suplementação dessa vitamina durante a gestação. } \\
\text { No caso de mães sem a deficiência de vitamina, a suplementação } \\
\text { de ácido fólico e multivitamínicos também reduziu os riscos de a } \\
\text { criança desenvolver TEA. Esse resultado foi observado, inclusive, } \\
\text { no caso de a mulher iniciar a suplementação dois anos antes do } \\
\text { momento em que deseja engravidar. }\end{array}$ & $\begin{array}{l}\text { Existe e permanece a redução do risco de desen- } \\
\text { volvimento do TEA pela criança quando, durante } \\
0 \text { período gestacional, há a suplementação de } \\
\text { ácido fólico e multivitamínicos, sobretudo se a } \\
\text { mãe apresentar deficiência de vitaminas. Contu- } \\
\text { do, não foi observada redução do risco quando } \\
\text { as mães com deficiência de vitaminas fizeram a } \\
\text { suplementação anteriormente à concepção, e não } \\
\text { durante a gestação. }\end{array}$ \\
\hline $\begin{array}{l}\text { Iglesias } \\
\text { Vázquez } \\
\text { etal. }\end{array}$ & 2019 & $\begin{array}{l}\text { Foi pesquisado sistematicamente o PubMed, } \\
\text { Scopus e The Cochrane Library até junho de } \\
\text { 2018, sem restrições de idioma. Diferenças } \\
\text { médias padronizadas e odds ratio com inter- } \\
\text { valos de confiança de 95\% são usadas para } \\
\text { descrever quaisquer associações entre ácido } \\
\text { fólico e desenvolvimento mental, desenvol- } \\
\text { vimento motor e TEA. }\end{array}$ & $\begin{array}{l}0 \text { principal achado foi que o uso pré-natal de ácido fólico foi asso- } \\
\text { ciado a uma redução de } 58 \% \text { no risco de TEA em crianças. As melho- } \\
\text { res pontuações para o desenvolvimento mental foram associadas à } \\
\text { baixa exposição pré-natal ao ácido fólico. }\end{array}$ & $\begin{array}{l}\text { Embora os resultados devam ser interpretados } \\
\text { com cautela, eles mostraram que os suplementos } \\
\text { pré-natais de rotina de ácido fólico estavam asso- } \\
\text { ciados a níveis significativamente mais baixos de } \\
\text { TEA. Mais estudos são necessários para se chegar } \\
\text { a uma conclusão firme, dada a etiologia multifa- } \\
\text { torial do neurodesenvolvimento. }\end{array}$ \\
\hline
\end{tabular}

\section{CONCLUSÃO}

Embora os sinais clínicos, que incluem dificuldade na comunicação e interação social, tenham sido descobertos há muitos anos, ainda é muito complexo entender qual ou quais seriam as principais causas do TEA. Além disso, o que parece ser um número no aumento de casos de TEA ao longo dos anos se deve ao fato de que mais fatores genéticos, como mutações no gene responsável pela síndrome do $X$ frágil e genes de novo, responsáveis por eventos neuronais, e fatores ambientais, como poluição, vêm sendo atribuídos ao transtorno.

No que concerne ao uso de ácido fólico antes e durante a gestação e sua possível relação com o aumento da incidência do TEA, um maior número de periódicos ressalta com mais precisão seus efeitos benéficos na prevenção dos defeitos do tubo neural e outras malformações.
Sendo assim, quando se analisa o risco-benefício da suplementação com ácido fólico na dose mínima diária de 0,4 $\mathrm{mg}(=400 \mu \mathrm{g})$, dois a três meses antes da concepção até o final da gestação, ou continuando ao longo do período de amamentação, conclui-se que os benefícios sobrepujam os possíveis malefícios. No entanto, mais pesquisas devem ser realizadas na tentativa de comprovar se o tempo e a quantidade do uso dessa vitamina podem estar implicados no desenvolvimento do TEA.

\section{CONTRIBUIÇÕES INDIVIDUAIS}

Fernanda das Chagas Angelo Mendes Tenorio - Atuou na revisão literária quanto aos tópicos "Aspectos epidemiológicos do TEA" e "Sinais e sintomas do TEA". 
José Reginaldo Alves de Queiroz Júnior - Auxiliou na revisão da literatura do tópico "Diagnóstico clínico e tratamento do TEA", além de ter contribuído na formatação das referências bibliográficas para o formato da presente revista.

Gyl Everson de Souza Maciel - Colaborou com a revisão da literatura do tópico "Fatores que desencadeiam o TEA".

Carina Scanoni Maia - Contribui com a composição dos tópicos "Metabolismo do ácido fólico" e "Ácido fólico na embriogênese", além de ter aprovado a versão final do presente trabalho.

Karina Maria Campello de Menezes - Foi responsável pela estruturação do tópico "Relação entre o uso do ácido fólico e o desenvolvimento do TEA" e demais partes do artigo, além de ter contribuído significativamente no desenho deste trabalho.

\section{CONFLITO DE INTERESSES}

Os autores afirmam não possuir conflito de interesses.

\section{REFERÊNCIAS}

1. Mello AMS. Autismo: guia prático. 8a ed. São Paulo: AMA/Brasília: CORDE; 2016.

2. Williams RJ. Sulfate deficiency as a risk factor for autism. J Autism Dev Disord. 2019

3. Griesi-Oliveira K, Sertié AL. Transtornos do espectro autista: um quia atualizado para aconselhamento genético. Einstein (São Paulo). 2017;15(2):233-8

4. Nazki FH, Sameer AS, Ganaie BA. Folate: metabolism, genes, polymorphisms and the associated diseases. Gene. 2014;533(1):11-20.

5. Moussa HN, Hosseini Nasab S, Haidar ZA, Blackwell SC, Sibai BM. Folic acid supplementation: what is new? Fetal, obstetric, long-term benefits and risks. Future Science OA. 2016:2(2):FS0116.

6. Rodier PM, Ingram JL, Tisdale B, Nelson S, Romano J. Embryological origin for autism: Developmental anomalies of the cranial nerve motor nuclei. J Comp Neurol. 1996;370(2):247-61.

7. Lotter V. Epidemiology of autistic conditions in young children. Soc Psychiatry. 1966;1(3):12435.

8. Gillberg C, Steffenburg S, Schaumann H. Is autism more common now than ten years ago? Br J Psychiatry. 1991;158:403-9.

9. Baird G, Simonoff E, Pickles A, Chandler S, Loucas T, Meldrum D, et al. Prevalence of disorders of the autism spectrum in a population cohort of children in South Thames: the Special Needs and Autism Project (SNAP). Lancet. 2006;368(9531):210-5.

10. Baxter AJ, Brugha TS, Erskine HE, Scheurer RW, Vos T, Scott JG. The epidemiology and global burden of autism spectrum disorders. Psychol Med. 2015;45(3):601-13.

11. Elsabbagh M, Divan G, Koh YJ, Kim YS, Kauchali S, Marcín C, et al. Global prevalence of autism and other pervasive developmental disorders: global epidemiology of autism. Autism Res. 2012:5(3):160-79.

12. Kim YS, Leventhal BL, Koh YJ, Fombonne E, Laska E, Lim EC, et al. Prevalence of autism spectrum disorders in a total population sample. Am J Psychiatry. 2011;168(9):904-12.

13. Christensen DL, Bilder DA, Zahorodny W, Pettygrove S, Durkin MS, Fitzgerald RT, et al. Prevalence and characteristics of autism spectrum disorder among 4-year-old children in the autism and developmental disabilities monitoring network. J Dev Behav Pediatr. 2016;37(1):1-8.

14. Zablotsky B, Black LI, Maenner MJ, Schieve LA, Blumberg SJ. Estimated Prevalence of Autism and Other Developmental Disabilities Following Questionnaire Changes in the 2014 National Health Interview Survey. Natl Health Stat Report. 2015;(87):1-20.
15. Idring S, Lundberg M, Sturm H, Dalman C, Gumpert C, Rai D, et al. Changes in prevalence of autism spectrum disorders in 2001-2011: findings from the Stockholm youth cohort. J Autism Dev Disord. 2015;45(6):1766-73.

16. Barbosa MRP, Fernandes FDM. Qualidade de vida dos cuidadores de crianças com transtorno do espectro autístico. Rev Soc Bras Fonoaudiol. 2009;14(4):482-6.

17. Oliveira C. Um retrato do autismo no Brasil. Espaço Aberto - USP; 2018. Disponível em: http://www.usp.br/espaçoaberto/?materia=um-retrato-do-autismo-no-brasil. Acesso em: 21 jun. 2018

18. Beck RG. Estimativa do número de casos de transtorno do espectro autista no sul do Brasil [dissertação]. Tubarão: Universidade do Sul de Santa Catarina; 2017.

19. Szatmari P, Chawarska K, Dawson G, Georgiades S, Landa R, Lord C, et al. Prospective longitudinal studies of infant siblings of children with autism: lessons learned and future directions. J Am Acad Child Adolesc Psychiatry. 2016;55(3):179-87.

20. Zwaigenbaum L, Bryson SE, Brian J, Smith IM, Roberts W, Szatmari P, et al. Stability of diagnostic assessment for autism spectrum disorder between 18 and 36 months in a highrisk cohort. Autism Res. 2016:9(7):790-800.

21. Zanon RB, Backes B, Bosa CA. Identificação dos primeiros sintomas do autismo pelos pais. Psicol Teor Pesq. 2014;30(1):25-33.

22. Backes B, Zanon RB, Bosa CA. Características sintomatológicas de crianças com autismo e regressão da linguagem oral. Psicol Teor Pesq. 2017;33(1).

23. Ozonoff S, Iosif AM, Baquio F, Cook IC, Hill MM, Hutman T, et al. A prospective study of the emergence of early behavioral signs of autism. J Am Acad Child Adolesc Psychiatry. 2010;49(3):256-66.e1-2

24. Werling DM, Geschwind DH. Sex differences in autism spectrum disorders. Curr Opin Neurol. 2013;26(2):146-53.

25. Frazier TW, Georgiades S, Bishop SL, Hardan AY. Behavioral and cognitive characteristics of females and males with autism in the simons simplex collection. J Am Acad Child Adolesc Psychiatry. 2014;53(3):329-40.e3.

26. Volkmar F, Siegel M, Woodbury-Smith M, King B, McCracken J, State M. Practice parameter for the assessment and treatment of children and adolescents with autism spectrum disorder. J Am Acad Child Adolesc Psychiatry. 2014;53(2):237-57.

27. Stepanova E, Dowling S, Phelps M, Findling RL. Pharmacotherapy of emotional and behavioral symptoms associated with autism spectrum disorder in children and adolescents. Dialogues Clin Neurosci. 2017;19(4):395-402.

28. Kasari C. Update on behavioral interventions for autism and developmental disabilities. Curr Opin Neurol. 2015;28(2):124-9.

29. Andalécio ACGSAM, Gomes CGS, Silveira AD, Oliveira IM, Castro RC. Efeitos de 5 anos de intervenção comportamental intensiva no desenvolvimento de uma criança com autismo. Rev Bras Educ Espec. 2019;25:389-402

30. Lovaas 0l. Behavioral treatment and normal educational and intellectual functioning in young autistic children. J Consult Clin Psychol. 1987;55(1):3-9.

31. Rutter M. Genetic influences and autism. In: Volkmar FR, Paul R, Klin A, Cohen D, eds. Handbook of autism and pervasive developmental disorders. 3rd ed. Hoboken, NJ: John Wiley \& Sons Inc.; 2013. p 425-52.

32. Frazier TW, Thompson L, Youngstrom EA, Law P, Hardan AY, Eng C, et al. A twin study of heritable and shared environmental contributions to autism. J Autism Develop Disord. 2014;44(8):2013-25.

33. Tick B, Bolton P, Happé F, Rutter M, Riisdijk F. Heritability of autism spectrum disorders: a meta-analysis of twin studies. J Child Psychol Psychiatry. 2016;57(5):585-95.

34. Chen JA, Peñagarikano 0, Belgard TG, Swarup V, Geschwind DH. The emerging picture of autism spectrum disorder: genetics and pathology. Annu Rev Pathol. 2015;10:111-44.

35. Schaefer GB, Mendelsohn NJ. Genetics evaluation for the etiologic diagnosis of autism spectrum disorders. Genet Med. 2008;10(1):4-12

36. Schaefer $\mathrm{G}$, Bradley M, Nancy J. Clinical genetics evaluation in identifying the etiology of autism spectrum disorders: 2013 guideline revisions. Genet Med. 2013;15(5):399-407.

37. Gilman SR, lossifov I, Levy D, Ronemus M, Wigler M, Vitkup D. Rare de novo variants associated with autism implicate a large functional network of genes involved in formation and function of synapses. Neuron. 2011;70(5):898-907.

38. Iossifov I, Ronemus M, Levy D, Wang Z, Hakker I, Rosenbaum J, et al. De novo gene disruptions in children on the autistic spectrum. Neuron. 2012;74(2):285-99. 
39. Sanders SJ, Ercan-Sencicek AG, Hus V, Luo R, Murtha MT, Moreno-De-Luca D, et al. Multiple recurrent de novo CNVs, including duplications of the 7q11.23 Williams syndrome region, are strongly associated with autism. Neuron. 2011;70(5):863-85.

40. Zoghbi HY. Postnatal neurodevelopmental disorders: meeting at the synapse? Science. 2003:302(5646):826-30.

41. Connors SL, Levitt P, Matthews SG, Slotkin TA, Johnston MV, Kinney HC et al. Fetal mechanisms in neurodevelopmental disorders. Pediatr Neurol. 2008;38(3):163-76.

42. Lyall K, Croen L, Daniels J, Fallin MD, Ladd-Acosta C, Lee BK, et al. The changing epidemiology of autism spectrum disorders. Annu Rev Public Health. 2017:38:81-102.

43. Jung CR, Lin YT, Hwang BF. Correction: air pollution and newly diagnostic autism spectrum disorders: a population-based cohort study in Taiwan. PLoS One. 2018;13(9):e0202996.

44. Guxens M, Ghassabian A, Gong T, Garcia-Esteban R, Porta D, Giorgis-Allemand L, et al. Air pollution exposure during pregnancy and childhood autistic traits in four european population-based cohort studies: The ESCAPE Project. Environ Health Perspect. 2016;124(1):133-40.

45. Dachew BA, Mamun A, Maravilla JC, Alati R. Pre-eclampsia and the risk of autism-spectrum disorder in offspring: meta-analysis. Br J Psychiatry. 2018;212(3):142-7.

46. Krakowiak P, Walker CK, Bremer AA, Baker AS, Ozonoff S, Hansen RL, et al. Maternal metabolic conditions and risk for autism and other neurodevelopmental disorders. Pediatrics. 2012:129(5):e1121-8.

47. Christensen J, Grønborg TK, Sørensen MJ, Schendel D, Parner ET, Pedersen LH, et al. Prenatal valproate exposure and risk of autism spectrum disorders and childhood autism. JAMA. 2013;309(16):1696-703.

48. Strömland K, Nordin V, Miller M, Akerström B, Gillberg C. Autism in thalidomide embryopathy: a population study. Dev Med Child Neurol. 1994;36(4):351-6.

49. Czeizel A, Dudás I, Vereczkey A, Bánhidy F. Folate deficiency and folic acid supplementation: the prevention of neural-tube defects and congenital heart defects. Nutrients. 2013:5(11):4760-75.

50. Hoffbrand AV, Weir DG. The history of folic acid. Br J Haematol. 2001;113(3):579-89.

51. Shane B. Folate chemistry and metabolism. In: Bailey LB, ed. Folate in health and disease. New York: Marcel Dekker; 1995. p. 1-22.

52. Blom HJ, Shaw GM, den Heijer M, Finnell RH. Neural tube defects and folate: case far from closed. Nat Rev Neurosci. 2006;7(9):724-31.

53. Melse-Boonstra A, de Bree A, Verhoef P, Bjørke-Monsen AL, Verschuren WMM. Dietary monoglutamate and polyglutamate folate are associated with plasma folate concentrations in Dutch men and women aged 20-65 years. J Nutr. 2002;132(6):1307-12.

54. Nazki FH, Sameer AS, Ganaie BA. Folate: metabolism, genes, polymorphisms and the associated diseases. Gene. 2014;533(1):11-20.

55. Brustolin S, Giugliani R, Félix TM. Genetics of homocysteine metabolism and associated disorders. Braz J Med Biol Res. 2010;43(1):1-7.

56. Ratan SK, Rattan KN, Pandey RM, Singhal S, Kharab S, Bala M, et al. Evaluation of the levels of folate, vitamin B12, homocysteine and fluoride in the parents and the affected neonates with neural tube defect and their matched controls. Pediatr Surg Int. 2008;24(7):803-8.

57. Fonseca VM, Sichieri R, Basilio L, Ribeiro LVC. Consumo de folato em gestantes de um hospital público do Rio de Janeiro. Rev Bras Epidemiol. 2003;6(4):319-27.

58. Mezzomo CLS, Garcias GL, Sclowitz ML, Sclowitz IT, Brum CB, Fontana T, et al. [Prevention of neural tube defects: prevalence of folic acid supplementation during pregnancy and associated factors in Pelotas, Rio Grande do Sul State, Brazill. Cad Saúde Pública. 2007:23(11):2716-26

59. Santos LMP, Pereira MZ. Efeito da fortificação com ácido fólico na redução dos defeitos do tubo neural. Cad Saúde Pública. 2007;23(1):17-24.

60. Waterland RA, Michels KB. Epigenetic epidemiology of the developmental origins hypothesis. Ann Rev Nutr. 2007;27:363-88.

61. Richmond RC, Sharp GC, Herbert G, Atkinson C, Taylor C, Bhattacharya S, et al. The longterm impact of folic acid in pregnancy on offspring DNA methylation: follow-up of the Aberdeen Folic Acid Supplementation Trial (AFAST). Int J Epidemiol. 2018.

62. Steenweg-de Graaff J, Roza SJ, Walstra AN, El Marroun H, Steegers EAP, Jaddoe VWV, et al. Associations of maternal folic acid supplementation and folate concentrations dur- ing pregnancy with foetal and child head growth: the Generation R Study. Eur J Nutr. 2017;56(1):65-75.

63. Centers for Disease Control and Prevention. Folic Acid. Disponível em: https://www.cdc. gov/ncbddd/folicacid/recommendations.html. Acesso em: 14 maio 2018.

64. Genetics Committee, Wilson RD, Audibert F, Brock JA, Carroll J, Cartier L, Gagnon A, et al. Pre-conception Folic Acid and Multivitamin Supplementation for the Primary and Secondary Prevention of Neural Tube Defects and Other Folic Acid-Sensitive Congenital Anomalies. J Obstet Gynaecol Can. 2015;37(6):534-52.

65. Sahakyan V, Duelen R, Tam WL, Roberts SJ, Grosemans H, Berckmans P, et al. Folic Acid Exposure Rescues Spina Bifida Aperta Phenotypes in Human Induced Pluripotent Stem Cell Model. Sci Rep. 2018;8(1):2942.

66. Maberly GF, Stanley FJ. Mandatory fortification of flour with folic acid: an overdue public health opportunity. Med J Aust. 2005;183(7):342-3.

67. Centers for Disease Control and Prevention (CDC). Neural tube defect surveillance and folic acid intervention - Texas-Mexico border, 1993-1998. MMWR Morb Mortal Wkly Rep. 2000;49(1):1-4.

68. Czeizel AE, Dudas I. Prevention of the first occurrence of neural-tube defects by periconceptional vitamin supplementation. N Engl J Med. 1992;327(26):1832-5.

69. Relton CL, Wilding CS, Laffling AJ, Jonas PA, Burgess T, Binks K, et al. Low erythrocyte folate status and polymorphic variation in folate-related genes are associated with risk of neural tube defect pregnancy. Mol Genet Metab. 2004;81(4):273-81.

70. Hernández-Díaz S, Werler MM, Walker AM, Mitchell AA. Folic acid antagonists during pregnancy and the risk of birth defects. N Engl J Med. 2000;343(22):1608-14.

71. Wald NJ, Morris JK, Blakemore C. Public health failure in the prevention of neural tube defects: time to abandon the tolerable upper intake level of folate. Public Health Rev.2018:39:2.

72. Brasil FB, Amarante LH, Oliveira MR. Maternal folic acid consumption during gestation and its long-term effects on offspring's liver: a systematic review. Rev Bras Saúde Matern Infant. 2017;17(1):7-15.

73. Virk J, Liew Z, Olsen J, Nohr EA, Catov JM, Ritz B. Preconceptional and prenatal supplementary folic acid and multivitamin intake and autism spectrum disorders. Autism. 2016;20(6):710-8.

74. Vilbiss EA, Gardner RM, Newschaffer (J, Lee BK. Maternal folate status as a risk factor for autism spectrum disorders: a review of existing evidence. Br J Nutr. 2015;114(5):663-72.

75. Spek AA. The influence of genes and environment on the development of autism spectrum disorders. Tijdschr Psychiatr. 2014;56(10):660-7

76. Castro K, Klein Lda S, Baronio D, Gottfried C, Riesgo R, Perry IS. Folic acid and autism: What do we know? Nutr Neurosci. 2016;19(7):310-7.

77. Neggers YH. Increasing prevalence, changes in diagnostic criteria, and nutritional risk factors for autism spectrum disorders. ISRN Nutr. 2014.

78. Lyall K, Schmidt RJ, Hertz-Picciotto I. Maternal lifestyle and environmental risk factors for autism spectrum disorders. Int J Epidemiol. 2014;43(2):443-64.

79. Braun JM, Froehlich T, Kalkbrenner A, Pfeiffer CM, Fazili Z, Yolton K, et al. Brief report: are autistic-behaviors in children related to prenatal vitamin use and maternal whole blood folate concentrations? J Autism Dev Disord. 2014;44(10):2602-7.

80. Neggers $Y$. The relationship between folic acid and risk of autism spectrum disorders. Healthcare (Basel). 2014;2(4):429-44.

81. Al-Farsi YM, Waly MI, Deth RC, Al-Sharbati MM, Al-Shafaee M, Al-Farsi 0, et al. Low folate and vitamin B12 nourishment is common in Omani children with newly diagnosed autism. Nutrition. 2013;29(3):537-41.

82. Schmidt RJ, Tancredi DJ, Ozonoff S, Hansen RL, Hartiala J, Allayee H, et al. Maternal periconceptional folic acid intake and risk of autism spectrum disorders and developmental delay in the CHARGE (CHildhood Autism Risks from Genetics and Environment) casecontrol study. Am J Clin Nutr. 2012;96(1):80-9.

83. Surén P, Roth C, Bresnahan M, Haugen M, Hornig M, Hirtz D, et al. Association between maternal use of folic acid supplements and risk of autism spectrum disorders in children. JAMA. 2013;309(6):570-7.

84. Strøm M, Granström C, Lyall K, Ascherio A, Olsen SF. Research Letter: Folic acid supplementation and intake of folate in pregnancy in relation to offspring risk of autism spectrum disorder. Psychol Med. 2018:48(6):1048-54. 
85. Levine SZ, Kodesh A, Viktorin A, Smith L, Uher R, Reichenberg A, et al. Association of maternal use of folic acid and multivitamin supplements in the periods before and during pregnancy with the risk of autism spectrum disorder in offspring. JAMA Psychiatry. 2018;75(2):176-84
86. Wood AG, Nadebaum C, Anderson V, Reutens D, Barton S, O'Brien TJ, et al. Prospective assessment of autism traits in children exposed to antiepileptic drugs during pregnancy. Epilepsia. 2015;56(7):1047-55.

87. Iglesias Vázquez L, Canals J, Arija V. Review and meta-analysis found that prenatal folic acid was associated with a $58 \%$ reduction in autism but had no effect on mental and motor development. Acta Paediatr. 2019;108(4):600-10. 